\title{
Acessos Vasculares e Infecção Relacionada à Cateter
}

\author{
Vascular Access and Catheter Associated Blood-Stream Infections
}

\author{
Marcelo Bonvento ${ }^{1}$
}

\section{RESUMO}

JUSTIFICATIVA E OBJETIVOS: A infecção da corrente sangüínea relacionada à cateter ocorre quando o germe presente no local de inserção atinge a corrente sangüínea, resultando em bacteremia, que quando não contida, provoca infecção com grave comprometimento clínico, podendo resultar em septicemia. Essa infecção a partir do cateter deve ser suspeitada quando não existe um foco infeccioso primário aparente e quando as hemoculturas (do sangue e da ponta do cateter), colhidas após $48 \mathrm{~h}$ de internação, resultarem no crescimento do mesmo agente infeccioso. O objetivo deste estudo foi revisar as principais recomendações para prevenção, diagnóstico e tratamento das infecções da corrente sangüínea relacionadas à cateteres.

CONTEÚDO: Serão apresentadas as atuais recomendações para a prevenção, o diagnóstico e o tratamento das infecções da corrente sangüínea relacionada a cateteres.

CONCLUSÕES: Consiste em problema freqüente em centro de terapia intensiva (CTI), contribuindo com a morbimortalidade hospitalar. A elaboração de protocolos para a prevenção e o controle dessas infecções, deve fazer parte da rotina dos CTI.

1. Centro de Terapia Intensiva do Hospital das Clínicas da Faculdade de Medicina de Ribeirão Preto / Unidade de Emergência.

*Recebido do Centro de Terapia Intensiva do Hospital das Clínicas da Faculdade de Medicina de Ribeirão Preto / Unidade de Emergência, Ribeirão Preto, SP.

Apresentado em 21 de agosto de 2006

Aceito para publicação em 05 de março de 2007

Endereço para correspondência:

Dr. Marcelo Bonvento

UTI Adulto Unidade de Emergência

Rua Bernardino de Campos, 1000

14015-130 Ribeirão Preto, SP

Fones: (16) 3602-1198 / 3602-1197

E-mail: mbonvento@uol.com.br

(C)Associação de Medicina Intensiva Brasileira, 2007
Unitermos: acessos vasculares, infecção da corrente sangüínea relacionada à cateter central.

\section{SUMMARY}

BACKGROUND AND OBJECTIVES: The catheter related infections occurs when the bacteria of the skin around the catheter reach the blood stream. The catheter related infection is suspected when there is no other evident site of infection and the cultures of the material collected from the catheter and the patient's blood show the same agent.

CONTENTS: The recommendations of prevention, diagnose and treatment of catheter related infections are presented in this article.

CONCLUSIONS: The catheter related infection is a relevant problem in intensive care units (ICU), contributing to a raise in hospital mortality. The elaboration of protocols to prevent and control these infections must be a routine in Intensive Care Unit.

Key Words: catheter-related blood stream infections, vascular access.

\section{INTRODUÇÃO}

Com o advento dos centros de terapia intensiva (CTI) ocorreu um avanço no tratamento do paciente crítico, promovendo menor mortalidade, mesmo em populações de maior risco, como na sepse, nos imunodeprimidos, nos pacientes oncológicos e naqueles submetidos à ventilação mecânica.

No entanto, a evolução do arsenal terapêutico, utilizando-se de técnicas cada vez mais invasivas, resultou em mecanismos de quebras de barreiras e exposição de tecidos previamente íntegros, tornando-os susceptíveis à infecção. A infecção relacionada ao cateter é um exemplo desta realidade. Ela ocorre quando há invasão da corrente sangüínea por um germe através da colonização do cateter venoso.

O objetivo deste estudo foi revisar as principais recomendações para a prevenção, o diagnóstico e o tratamento das infecções da corrente sangüínea relacionadas à cateteres. 


\section{EPIDEMIOLOGIA}

Nos países desenvolvidos a taxa de infecção hospitalar (por todas as causas) oscila em $5 \%$ a $8 \%$. No estudo The prevalence of infection in intensive care units (EPIC study), envolvendo 10038 pacientes em 1417 CTI da Europa, foi observado que as infecções da corrente sangüínea representam $12 \%$ das infecções hospitalares ( $4^{\text {a }}$ causa), sendo responsável por $14 \%$ a $38 \%$ dos óbitos relacionados às infecções hospitalares ${ }^{1}$.

Com relação à infecção da corrente sangüínea relacionada à cateter, as taxas de infecção variam de acordo com o local de implante, o tipo de cateter empregado, a categoria do CTI (queimados, trauma, pós-operatório) e as comorbidades dos pacientes. Nas pesquisas coordenadas pelo National Nosocomial Infections Surveillance System (NNISS) essas infecções são prevalentes em unidades de atendimento a queimados (12,8\% por 1000 cateteres/dia) comparados a unidades de pós-operatório de cirurgia cardíaca e de tórax $(2,8 \%)$. Estudos comparando pacientes clínicos e cirúrgicos mostram que a taxa de infecção da corrente primária em pacientes cirúrgicos é de $31 \%$ versus $24 \%$ relacionados à presença do cateter e o seu tempo de permanência. Assim como as pneumonias, as infecções relacionadas à cateter são as infecções hospitalares de alto custo e letais.

\section{PATOGÊNESE DAS INFECÇÕES RELACIONADAS À CATETERES}

Envolve a presença de um agente infeccioso, um veículo de inoculação e a quebra de barreira. Dentre as espécies microbianas mais prevalentes temos: Staphylococcus coagulase negativo $(27 \%)$, S. aureus (16\%), Enterococcus (8\%), Gram-negativos (19\%), E. coli (6\%), Enterobacter spp (5\%), P. aeruginosa (4\%), K. pneumoniae (4\%) e Candida spp (8\%).

Os mecanismos de colonização do cateter podem ocorrer de duas formas:

a) A superfície externa do cateter, túnel subcutâneo e a pele circunvizinha podem ser colonizados através da microbiota própria da pele, das mãos dos profissionais e dos anti-sépticos contaminados (quanto maior o número de bactérias, maior a probabilidade de infecção). b) Superfície interna: a propagação de bactérias pela superfície interna do cateter pode ocorrer por dois mecanismos principais:

- Manipulação inadequada do canhão do cateter, tam- bém chamado de hub;

- Contaminação das soluções de infusão por manipulação direta da substância administrada ou durante o processo de fabricação industrial da solução (neste caso terá caráter endêmico).

\section{DIAGNÓSTICO - TIPOS DE INFECÇÕES RELACIO- NADAS À CATETERES}

1. Infecção hospitalar primária da corrente sangüínea: a) Infecção em pacientes com hemocultura positiva colhida $48 \mathrm{~h}$ após a hospitalização, com importância clínica e sem foco primário aparente; b) Pode significar bacteremia temporária de um foco infeccioso (que pode se resolver espontaneamente) ou pode resultar em sepse (se não for contida);

2. Infecção do local de inserção do cateter: eritema, induração ou secreção purulenta ao redor da pele no local de sua inserção e/ou febre;

3. Infecção no túnel dos cateteres implantados: eritema, dor, induração nos tecidos que cobrem o cateter maior que $2 \mathrm{~cm}$ do local de sua inserção, associada ou não à febre.

4. Cateter colonizado: crescimento maior ou igual a 15 (unidades formadoras de colônias - UFC) semiquantitativa (Maki roll) ou maior que $10^{3}$ (quantitativa), de segmento distal, na ausência de sinais clínicos. É obrigatório que a remoção do cateter ocorra após 48 a $72 \mathrm{~h}$ de inserção, porque se ocorrer antes de $48 \mathrm{~h}$ será considerado preparo ineficiente do local de sua inserção (assepsia ou anti-sepsia), no momento do implante';

5. Infecção da corrente sangüínea relacionada ao cateter: isolamento do mesmo agente em cultura do segmento distal do cateter (cultura semiquantitativa ou quantitativa) e no sangue, acompanhado de sintomas clínicos de infecção da corrente sangüínea sem outro foco aparente de infecção? .

6. Infecção em dispositivo implantável: eritema e necrose da pele acima do reservatório do dispositivo ou exsudato purulento na bolsa subcutânea.

\section{TRATAMENTO}

\section{Paciente com Suspeita de Infecção Relacionada à Cateter}

Quando não existe um foco identificado, deve-se coIher duas amostras de hemoculturas de sangue periférico e retirar o cateter e enviar a ponta $(5 \mathrm{~cm}$ distal) para cultura (MAKI roll). 
A tomada de decisão e a interpretação dos dados devem ser, sempre que possível, baseadas nos resultados das culturas para garantir tratamento correto ${ }^{3}$, conforme descrito a seguir:

1. Quando a ponta de cateter não apresenta crescimento: a infecção da corrente sangüínea relacionada ao cateter é improvável, mesmo com hemocultura positiva (pensar em outro local de bacteremia);

2. Quando a ponta de cateter apresenta crescimento: é importante considerar o resultado da hemocultura do sangue periférico para a correta interpretação, assim pode-se ter:

- Hemocultura sem evidência de crescimento de germes: existe a colonização do cateter. Está autorizada a troca do local de inserção, com novo cateter e a antibioticoterapia não deve ser instituída;

- Hemocultura com crescimento do mesmo germe do cateter: existe infecção da corrente sangüínea relacionada a cateter e está indicado uso de antibiótico, se os sintomas persistirem mesmo após a retirada do cateter ou se o paciente apresentar instabilidade hemodinâmica.

Não colher sangue venoso da luz do cateter objetivando realizar sua hemocultura, pois não diferencia colonização do cateter de infecção da corrente sangüínea relacionada à cateter.

$\mathrm{Na}$ impossibilidade da retirada do cateter (caso o paciente apresente coagulopatia, discrasias sangüíneas ou se tratando de cateteres implantáveis ou semi-implantáveis), exclusivamente nesses casos, autoriza-se a colher sangue venoso da luz do cateter (uma amostra) e enviar para realização de hemocultura; além da coleta de duas amostras de sangue periférico para hemocultura (sensibilidade baixa 75\%). Nesses casos, considera-se infecção da corrente sangüínea relacionada à cateter quando ocorrer o isolamento do mesmo germe em quantidade cinco vezes maior do cateter em relação ao sangue ${ }^{2}$ ou o tempo de positivação da hemocultura em sistema automático for menor que duas horas, comparativamente de sangue no cateter que no sangue periférico.

A técnica incorreta de inserção dos acessos centrais e a manutenção dos cateteres sem critérios definidos aumentam a probabilidade de colonização do local e o risco para desenvolver infecção da corrente sangüínea relacionada ao cateter ${ }^{4,5}$.

\section{Condições Especiais}

- Presença de eritema ou pus com quadro de sepse ou choque séptico: está autorizado uso de antibiotico- terapia empírica. Colher hemoculturas de sangue periférico, trocar o local do cateter e enviar a sua ponta para cultura;

- Instituir tratamento empírico para Staphilococcus aureus ou S. epidermidis. Imuno-comprometidos ou neutropênicos: cobrir bactérias Gram-negativas.

\section{PARTICULARIDADES DO CATETER EM RELAÇÃO À INFECÇÃO}

- Nos cateteres de múltiplas vias, quanto maior o número de lumens maior o risco de infecção6;

- A heparina intra-luminal evita o depósito de fibrina que é responsável pela nidação das bactérias²;

- Estudos realizados com o uso intra-luminal de antimicrobianos com o objetivo de prevenir a infecção mostraram um acréscimo do tempo do primeiro episódio de bacteremia, porém resultando em maior pressão seletiva de germes ${ }^{2}$;

- Cateteres recobertos com balonete (sulfadiazina de prata/clorexidina, minociclina/rifampicina ou com metais tipo prata ou platina), apresentaram redução do risco de infecção, comparados aos cateteres comuns. São indicados em pacientes queimados, neutropênicos, transplantados de medula óssea ou em hemodiálise por mais de 30 dias $^{2}$;

- Estudos in vitro demonstraram que os cateteres fabricados com polivinil cloridrato ou polietileno são menos resistentes à aderência de microorganismos do que aqueles constituídos por teflon, silicone e poliuretano?.

\section{PREVENÇÃO - Graus de Recomendação}

O Centers of Disease Control and Prevention (CDC) divide as recomendações por categorias conforme ${ }^{2}$ o quadro 1.

Quadro 1 - Níveis de Recomendações

\begin{tabular}{ll}
\hline Categoria & \multicolumn{1}{c}{ Recomendação } \\
\hline IA & $\begin{array}{l}\text { Apoiada por trabalhos experimentais ou estudos } \\
\text { epidemiológicos bem definidos }\end{array}$ \\
IB & $\begin{array}{l}\text { Definida como consenso por especialistas, com } \\
\text { forte razão teórica e evidência científica }\end{array}$ \\
II & $\begin{array}{l}\text { Estudos clínicos ou epidemiológicos ou por estu- } \\
\text { dos aplicáveis a alguns hospitais }\end{array}$ \\
Nenhuma & Práticas com evidências insuficientes \\
\hline
\end{tabular}

\section{ASSEPSIA E ANTI-SEPSIA}

Atualmente o Ministério da Saúde recomenda uso de degermantes químicos no cuidado a pacientes críti- 
cos e antes da realização de procedimentos invasivos, que agem na microbiota da pele e não dependem da ação mecânica da escovação, diminuindo a agressão à pele dos profissionais de saúde. Além disso, a maioria das formulações químicas dos degermantes possui efeitos residuais e cumulativos local, retardando o processo de re-colonização, que varia de quatro a seis horas.

A punção do acesso deve ser precedida pela higienização das mãos (categoria IA), paramentação completa (gorro, máscara, avental longo estéril, luvas e óculos de proteção), degermamação do local de inserção e anti-sepsia em campo ampliado (categoria IB).

\section{RECOMENDAÇÕES DO GUIDELINES (2002) PARA PREVENÇÃO DE INFECÇÃO DA CORRENTE San- güínea RELACIONADA À CATETER}

- Treinamento e educação continuada da equipe de saúde; vistoria rotineira diária do local de inserção durante os curativos (categoria IA); questionar se o paciente sente desconforto no local e anotar o tempo de permanência do cateter (categoria IB);

- Não realizar culturas rotineiras das pontas dos cateteres sem que exista dúvida clínica sugestiva de infecção;

- Remoção precoce dos cateteres, caso não sejam mais necessários;

- Se ocorrer mal funcionamento do cateter, a troca do acesso central deverá ser realizada com nova punção, não é recomendada a troca por fio guia;

- Segundo as últimas diretrizes sobre sepse ${ }^{8}$ a antibioticoterapia empírica deverá sempre levar em conta os germes mais prevalentes da instituição, de acordo com as recomendações da Comissão de Controle de Infecção Hospitalar (CClH).

\section{RECOMENDAÇÕES DE CURATIVOS E TROCA DE CATETERES}

\section{Protocolo da CCIH do Hospital das Clínicas de Ri- beirão Preto}

- Nas 24 h iniciais após a punção central, usar curativo oclusivo com gaze, porque pode ocorrer sangramento ou solução de continuidade. Após $24 \mathrm{~h}$, é recomendado trocar o curativo de gaze por curativo com filme plástico, com troca programada para 5 a 7 dias;

- A fixação do cateter impede a sua movimentação sobre o seu ponto de inserção na pele, evitando a mi- gração de bactérias da flora local sobre a superfície externa (categoria IB);

- Usar técnica asséptica para manipulação dos cateteres e conexões (higienizar o hub com álcool a 70\%) (categoria IB);

- O Center Disease Control and Prevention (CDC) não recomenda a troca rotineira de acessos centrais. Sempre avaliar a necessidade da manutenção do acesso central';

- A retirada do cateter em pacientes apenas com febre não é recomendada, pois pode acarretar complicações mecânicas relacionadas com novas punções;

- Remover o cateter quando houver suspeita de infecção local na pele, colonização ou de infecção da corrente sangüínea relacionada ao seu uso;

- Nos pacientes com traqueostomia, ou quando a cateterização for necessária por período prolongado, é preferível a utilização da veia subclávia (menor incidência de contaminação do cateter);

- Álcool gel deve ser usado antes do contato com os pacientes, previamente ao preparo de medicações e como complemento, após a higienização das mãos de procedimentos invasivos de curta duração.

\section{PREVENÇÃO DE INFECÇÃO DA CORRENTE SAN- GÜÍNEA RELACIONADA A CATETERES DE DIETA PARENTERAL}

- Via de acesso exclusiva (não usar torneirinhas);

- Manipulação asséptica;

- Troca do equipo a cada $24 \mathrm{~h}$;

- Troca de soluções exclusivas de emulsão lipídicas a cada $24 \mathrm{~h}$, correr em $6 \mathrm{~h}$ e no máximo a cada $12 \mathrm{~h}$; - Apresenta risco para infecção considerável, devido à alta concentração de carboidratos e proteínas (média de $5 \%$, podendo chegar a $14 \%$ ).

\section{CATETERES DE DIÁLISE}

Nos cateteres usados em diálises têm-se as seguintes recomendações ${ }^{2}$ :

- Uso exclusivo para diálise, proteção da via de entrada (exceto emergência);

- Preferir fístulas para hemodiálise em comparação com cateteres;

- Cateteres tipo Hickman ou Broviac se a permanência for maior que 30 dias;

- Hemoderivados devem ser administrados no máximo em $4 \mathrm{~h}$ e a troca do equipo deve ser feita ao término da infusão². 


\section{PERSPECTIVAS FUTURAS}

\section{Estratégias para Prevenção de Resistência Antimi- crobiana em UTI}

Podem ser divididas em estratégias não farmacológicas (como a higiene rotineira das mãos e implementação de protocolos de prevenção específicos) e estratégias de manuseio de antibióticos ${ }^{9}$ (evitar o seu uso prolongado e buscar sempre cobrir o espectro adequadamente, baseado em resultado de cultura).

O tratamento empírico deve-se basear na monitorização da resposta clínica do paciente, até que se possa dirigir a terapêutica baseada no antibiograma. Existem alguns estudos que sugerem benefício de fazer o rodízio dos antibióticos utilizados, devendo se abandonar determinada classe por um período ou manter um constante rodízio das classes de antibióticos ${ }^{10,11}$, embora não haja consenso na literatura.

\section{CONCLUSÃO}

As medidas que visam diminuir os riscos de infecção associada com a terapêutica por via venosa devem levar em conta a segurança do paciente e a relação custo-benefício. A educação continuada e a formação de equipes especializadas parecem ser uma maneira racional de prevenção dessas infecções, além do correto manuseio da antibioticoterapia visando suprimir a pressão seletiva dos germes. A elaboração de protocolos para a prevenção e o controle dessas infecções, deve fazer parte da rotina dos CTI.

\section{REFERÊNCIAS}

01. Cal RGR, Camargo LFA, Knobel E - Infecção da Corrente Sangüínea Relacionada a Cateter: Infectologia e Oxigenoterapia Hiperbárica.Rio de Janeiro, Atheneu 2003;4:49-64.

02. O'Gray NP, Alexander M, Dellinger EP et al - Prevention guidelines for catheter-related infections. Clin Infect Dis, 2002;35:1281-1307.

03. McGee DC, Gould MK - Preventing complications of central venous catheterization. N Engl J of Med, 2003;348:1123-1133.

04. Sherertz RJ, Ely EW, Westbrook DM et al - Education of physicians intraining can decrease the risk for vascular catheter infection. Ann Intern Med, 2000;132:641-648.

05. Vincent JL, Abraham E, Annane D et al - Reducing mortality in sepsis: new directions. Crit Care 2002;6:(Suppl3):S1-S18.

06. Dobbins BM, Catton JA, Kite P et al - Each lumen is a potential source of ventral venous catheter-related bloodstream infection. Crit Care Med, 2003;31:1688-1690.

07. Sheth NK, Franson TR, Rose HD et al - Colonization of bacteria on polyvinyl chloride and Teflon intravascular catheters in hospitalized patients. J Clin Microbiol, 1983;18:1061-1063.

08. Vincent JL, Dellinger RP Jean M et al - Surviving sepsis campaign guidelines for management of severe sepsis and septic shock. Crit Care Med, 2004;32:858-873.

09. Kollef MH, Micek ST - Strategies to prevent antimicrobial resistance in the intensive care unit. Crit Care Med, 2005;33:1845-1853.

10. Bergstrom CT, Lo M, Lipsitch M - Ecological theory suggests that antimicrobial cycling will not reduce antimicrobiol resistance in hospitals. Proc Nath Acad Sci USA. 2004,101:13285-13290. 